\title{
Biochemical and biophysical properties of a metagenome-derived GH5 endoglucanase displaying an unconventional domain architecture
}

\author{
Agnes C. Pimentel ${ }^{\mathrm{a}, \mathrm{b}}$, Gabriela C.G. Ematsu ${ }^{\mathrm{a}}$, Marcelo V. Liberato ${ }^{\mathrm{a}}$, Douglas A.A. Paixão ${ }^{\mathrm{a}, \mathrm{b}}$, \\ João Paulo L. Franco Cairo ${ }^{\mathrm{a}, \mathrm{b}}$, Fernanda Mandelli ${ }^{\mathrm{a}}$, Robson Tramontina ${ }^{\mathrm{a}, \mathrm{c}}$, \\ César A. Gandin ${ }^{\mathrm{d}}$, Mario de Oliveira Neto ${ }^{\mathrm{d}}$, Fabio M. Squina ${ }^{\mathrm{a}, * *}$, Thabata M. Alvarez ${ }^{\mathrm{a}, *}$ \\ a Laboratório Nacional de Ciência e Tecnologia do Bioetanol (CTBE), Centro Nacional de Pesquisa em Energia e Materiais (CNPEM), Caixa Postal 6192, CEP \\ 13083-970, Campinas, São Paulo, Brazil \\ ${ }^{\mathrm{b}}$ Departamento de Bioquímica, Instituto de Biologia (IB), Universidade Estadual de Campinas (UNICAMP), R. Monteiro Lobato, 255 - Cidade Universitária, \\ Campinas, São Paulo, Brazil \\ c Programa de Pós Graduação em Biociências e Tecnologia de Produtos Bioativos (BTPB), Instituto de Biologia (IB) - CP 6109, Universidade Estadual de \\ Campinas (UNICAMP), 13083-970, Campinas, SP, Brazil \\ d Departamento de Física e Biofísica, Instituto de Biociências de Botucatu, UNESP Univ Estadual Paulista, Distrito de Rubião Jr. s/n, Botucatu, SP, Brazil
}

\section{A R T I C L E I N F O}

\section{Article history:}

Received 19 July 2016

Received in revised form 5 February 2017

Accepted 6 February 2017

Available online 24 February 2017

\section{Keywords:}

Lignocellulosic biomass

Glycoside hydrolase family 5

Calx-beta domain

\begin{abstract}
A B S T R A C T
Endoglucanases are key enzymes in the degradation of cellulose, the most abundant polymer on Earth. The aim of this work was to perform the biochemical and biophysical characterization of CelE2, a soil metagenome derived endoglucanase. CelE2 harbors a conserved domain from glycoside hydrolase family 5 (GH5) and a C-terminal domain with identity to Calx-beta domains. The recombinant CelE2 displayed preference for hydrolysis of oat beta-glucan, followed by lichenan and carboxymethyl cellulose. Optimum values of enzymatic activity were observed at $45^{\circ} \mathrm{C}$ and $\mathrm{pH}$ 5.3, and CelE2 exhibited considerable thermal stability at $40^{\circ} \mathrm{C}$ for up to $360 \mathrm{~min}$. Regarding the cleavage pattern on polysaccharides, the release of oligosaccharides with a wide degree of polymerization indicated a characteristic of endoglucanase activity. Furthermore, the analysis of products generated from the cleavage of cellooligosaccharides suggested that CelE2 exhibited transglycosylation activity. Interestingly, the presence of $\mathrm{CaCl}_{2}$ positively affect CelE2, including in the presence of surfactants. SAXS experiments provided key information on the effect of $\mathrm{CaCl}_{2}$ on the stability of CelE2 and dummy atom and rigid-body models were generated. To the best of our knowledge this is the first biochemical and biophysical characterization of an endoglucanase from family GH5 displaying this unconventional modular organization.
\end{abstract}

(c) 2017 Elsevier B.V. All rights reserved.

\footnotetext{
* Corresponding author. Present address: Universidade Positivo, Master in Industrial Biotechnology, R. Prof. Pedro Viriato Parigot de Souza, 5300, Cidade Industrial, 81280-330, Curitiba, Paraná, Brazil.

** Corresponding author. Laboratório Nacional de Ciência e Tecnologia do Bioetanol (CTBE), Centro Nacional de Pesquisa em Energia e Materiais (CNPEM), Caixa Postal 6192, CEP 13083-970, Campinas, São Paulo, Brazil.

E-mail addresses: agnescristinap@gmail.com (A.C. Pimentel), gabriela.ematsu@bioetanol.org.br (G.C.G. Ematsu), marcelovliberato@gmail.com (M.V. Liberato), douglas.paixao@bioetanol.org.br (D.A.A. Paixão), jpcairo@gmail.com (J.P.L. Franco Cairo), fernanda.mandelli@bioetanol.org.br (F. Mandelli), robson.tramontina@gmail.com (R. Tramontina), cesargandin@gmail.com (C.A. Gandin), mario.neto@ibb.unesp.br (M. de Oliveira Neto), fmsquina@gmail.com (F.M. Squina), thabata.alvarez@up.edu.br (T.M. Alvarez).
}

\section{Introduction}

The main drivers for the development of renewable energy sources are the high dependence on nonrenewable energy sources coupled with their price fluctuation and environmental concerns regarding the emission of greenhouse gases from burning of fossil fuels [1]. In this context, lignocellulosic biomass represents a promising renewable source for the production of biofuels $[2,3]$.

Lignocellulosic biomass is typically composed of $40-60 \%$ cellulose, 20-40\% hemicellulose, 10-25\% lignin and minor amounts of ash, acids and extractives [4]. The production of biofuel from lignocellulosic biomass involves deconstruction of the plant cell wall and depolymerization of cellulose and hemicellulose into monomeric sugars through a combination of physicochemical pre-treatment and enzymatic hydrolysis [4,5]. Glycoside hydrolase (GH) is a class 
of enzymes with fundamental importance for the hydrolysis of cellulose and hemicelluloses. Since the degradation of these components is part of many biological reactions in nature, a variety of organisms are able to produce enzymes with versatile specificities and biochemical properties [6-8].

The classical scheme for hydrolytic cellulose degradation involves at least three types of enzyme activities working synergistically: (i) endo-1,4- $\beta$-glucanases, which randomly cleave internal bonds of the cellulose chain, (ii) exo-1,4- $\beta$-glucanases, which hydrolyze the external bonds of the reducing or non-reducing end of the chain and (iii) $\beta$-glucosidases, that cleave cellobiose molecules to glucose [9]. Recently, lytic polysaccharide monooxygenases (LPMOs) have been recognized as important players in the improvement of cellulose degradation by acting in synergy with cellulases $[9,10]$.

Representatives of endoglucanases are distributed in a variety of GH families accordingly to the CAZy (Carbohydrate Active Enzymes) database [11]. Of these, GH5 is one of the largest family in terms of number of members, taxonomic dispersion and substrate specificity, and has been the target of several studies, since it contemplates important activities for deconstruction of carbohydrates from the plant cell $[12,13]$.

Commonly, enzymes involved in plant cell wall degradation display multi-modular organization, which includes the catalytic domain and accessory domains such as carbohydrate binding modules (CBMs), the most well studied type of accessory domain, fibronectin type III domain (Fn3), immunoglobulin-like domain (Iglike) and Calx-beta domains, whose functions are still not fully elucidated [14-19].

In this context, the aim of this work was to perform comprehensive biochemical and biophysical characterization of CelE2, a modular cellulase derived from soil metagenome composed by an $\mathrm{N}$-terminal GH5 domain and a C-terminal with identity to Calx-beta domains.

\section{Materials and methods}

\subsection{Sequence and architecture analysis}

The cele2 gene was identified after functional screening on carboxymethyl cellulose of a soil-derived metagenomic library, as described previously [20]. Plasmid from the positive clone was extracted and submitted to DNA sequencing in an Applied Biosystems 3500xL Genetic Analyzer at the Brazilian Bioethanol Science and Technology Laboratory. The sequences generated were analyzed in Geneious Pro 5.6.2 (http://www.geneious.com) [21] for identification of the coding DNA sequence (CDS). The nucleotide sequence from the predicted CDS was compared to the NCBI database using the BLASTX tool and deposited in the NCBI GenBank (accession number KU715986). The modular architecture of CelE2 was evaluated in further details by comparison with PFAM and SMART databases [22-24]. Predictions of the signal peptide and biochemical and biophysical parameters were performed via SignalP 4.1 [25] and Protparam tool from ExPASy [26], respectively.

In order to perform orthologous group annotation, protein sequence was compared against the Eggnog database [27]. For phylogenetic analysis, protein sequences from the respective orthologous group were downloaded and used for construction of the phylogenetic tree in Mega 6.06 [28] using the neighbor-joining method [29].

\subsection{Cloning, heterologous expression and protein purification}

The coding DNA sequence of CelE2 was PCR-amplified using the forward primer 5' TATAGCTAGCCTGAGTATCTCGGATGCC 3 ' and reverse primer 5' ATAAAGCTTTTAGGCGCTACCCACCCGATC 3', containing NheI and HindIII restriction sites (underlined in the primers, respectively). The amplified gene was cloned into expression vector pET-28a (Novagen), in fusion with an N-terminal 6-His tag. Subsequently to the transformation in Escherichia coli Rosetta-gami ${ }^{\mathrm{TM}}$ 2 (Novagen), heterologous expression was performed by cultivation of cells in LB broth containing $50 \mu \mathrm{g} \mathrm{mL}^{-1}$ kanamycin and $40 \mu \mathrm{g} \mathrm{mL}^{-1}$ chloramphenicol, at $37^{\circ} \mathrm{C}$ and $200 \mathrm{rpm}$ until the $\mathrm{OD}_{600}$ reached 0.6-0.8. Afterward, IPTG was added at a final concentration of $1 \mathrm{mM}$ to induce expression and the temperature and agitation speed were reduced to $18{ }^{\circ} \mathrm{C}$ and $180 \mathrm{rpm}$, respectively, for approximately $16 \mathrm{~h}$. Then, the culture was centrifuged at 35,250 $\times \mathrm{g}$ for $30 \mathrm{~min}$ at $4{ }^{\circ} \mathrm{C}$ and the recovered cells were resuspended in $20 \mathrm{mM}$ Tris- $\mathrm{HCl}$ (pH 7.5), $200 \mathrm{mM} \mathrm{NaCl}, 20 \%$ glycerol and $5 \mathrm{mM}$ imidazole followed by cell disruption in an ultra sonicator (Sonics Vibra-Cell ${ }^{\mathrm{TM}}$ ). The first step of purification consisted of affinity chromatography that involved incubation of the recovered supernatant with TALON resin (Clontech) followed by elution of proteins with $20 \mathrm{mM}$ Tris- $\mathrm{HCl}$ (pH 8.0), $200 \mathrm{mM} \mathrm{NaCl}, 20 \%$ glycerol and $100 \mathrm{mM}$ imidazole. Next, the protein sample was further purified by size exclusion chromatography using a Superdex 75 10/300 GL column (GE Healthcare), equilibrated with $20 \mathrm{mM}$ sodium phosphate buffer ( $\mathrm{pH} 7.4$ ) containing $50 \mathrm{mM} \mathrm{NaCl}$. The purity of the collected protein fractions was assessed by SDS-PAGE [30] and quantification was performed by absorbance at $280 \mathrm{~nm}$, considering the predicted extinction coefficient of CelE2 $\left(123300 \mathrm{M}^{-1} \mathrm{~cm}^{-1}\right)$.

\subsection{Biochemical characterization}

In all steps of biochemical characterization the hydrolytic activity was determined by quantification of the amount of reducing sugar released according to the 3,5-dinitrosalicylic acid method [31], and all the assays were carried out at least in triplicate.

First, the enzymatic activity was analyzed in reactions $(100 \mu \mathrm{L})$ with different soluble polysaccharides $0.25 \%(\mathrm{w} / \mathrm{v})$ (purchased from Megazyme and Sigma-Aldrich) in $40 \mathrm{mM}$ of sodium acetate buffer $\mathrm{pH} 5.5$, for $60 \mathrm{~min}$ at $40^{\circ} \mathrm{C}$. For evaluation of temperaturedependence, reactions containing oat $\beta$-glucan $0.25 \%(\mathrm{w} / \mathrm{v})$ (Megazyme) in $40 \mathrm{mM}$ sodium acetate buffer pH 5.5 were incubated in a range of $15-90^{\circ} \mathrm{C}$ for $30 \mathrm{~min}$. The influence of different $\mathrm{pH}$ values on enzymatic activity was evaluated in $40 \mathrm{mM}$ sodium acetate buffer ( $\mathrm{pH} 3.6-5.6)$ and $40 \mathrm{mM}$ sodium phosphate buffer ( $\mathrm{pH} 5.8-8.0)$, in reactions containing oat $\beta$-glucan $0.25 \%(\mathrm{w} / \mathrm{v})$ followed by incubation at $45^{\circ} \mathrm{C}$ for $60 \mathrm{~min}$.

After these initial characterization steps, all assays were performed in oat $\beta$-glucan $0.25 \%(\mathrm{w} / \mathrm{v}$ ) and at the optimal $\mathrm{pH}$ and temperature. Thermal stability was assessed by incubation of CelE2 in $20 \mathrm{mM}$ sodium phosphate buffer ( $\mathrm{pH} 7.4$ ) containing $50 \mathrm{mM} \mathrm{NaCl}$ at temperatures ranging from $40^{\circ} \mathrm{C}-90^{\circ} \mathrm{C}$, followed by the collection of aliquots at regular times for measurement of residual activity by incubation for $30 \mathrm{~min}$ at optimal conditions.

The effect of different metal ions on enzymatic activity was evaluated by addition of compounds to be tested in the final concentration of $5 \mathrm{mM}$ [32], followed by incubation for $60 \mathrm{~min}$ at $45^{\circ} \mathrm{C}$. Considering that small variations of the concentration of ions present on purified CelE2 may interfere in the assays of ion supplementation, two independent experiments were performed. For analysis of the chelating effect, an enzyme solution was treated with final concentrations of $1 \mathrm{mM}, 5 \mathrm{mM}$ and $10 \mathrm{mM}$ EDTA (Ethylenediaminetetraacetic acid - Calbiochem) for $60 \mathrm{~min}$ at $5^{\circ} \mathrm{C}$. Next, reactions containing EDTA-treated enzyme were incubated for $30 \mathrm{~min}$ at $45^{\circ} \mathrm{C}$ for determination of residual enzymatic activity. Additionally, $\mathrm{CaCl}_{2}$ (5 mM final concentration) were added in reactions containing EDTA-treated enzyme in order to evaluate the ability of this metal salt to restore the enzymatic activity. Lastly, the enzymatic activity of CelE2 was evaluated in the presence of 
1\% (v/v) Triton ${ }^{\mathrm{TM}} \mathrm{X}-100$ (Sigma-Aldrich) and $1 \mathrm{mM}$ SDS (Sodium Dodecyl Sulfate - Merck), with incubation for $60 \mathrm{~min}$ at $45^{\circ} \mathrm{C}$. Reactions containing these agents were also evaluated with supplementation of $5 \mathrm{mM} \mathrm{CaCl}_{2}$. Comparisons of enzymatic activity in the presence and absence of compounds were assessed by performing the unpaired Student $t$ test using GraphPad Prism version 7.00, GraphPad Software, La Jolla California USA, www.graphpad.com.

\subsection{Analysis of the cleavage pattern by capillary zone electrophoresis}

The cleavage pattern was determined by evaluation of the hydrolysis products released after overnight incubation (at $45^{\circ} \mathrm{C}$ ) with $5 \mathrm{mM}$ of oligosaccharides (cellobiose $-\mathrm{C} 2$, cellotriose $-\mathrm{C} 3$, cellotetraose - C4 and cellopentaose - C5, all from Megazyme), $0.25 \%(\mathrm{w} / \mathrm{v})$ oat $\beta$-glucan and $10 \%(\mathrm{w} / \mathrm{v})$ Avicel PH-101 (Sigma Aldrich). Following incubation, the soluble fractions from the reactions were recovered and derivatized with 8-aminopyrene1,3,6-trisulfonic acid trisodium salt (APTS, Sigma-Aldrich) by reductive amination [33]. Separations were performed using a $\mathrm{P} / \mathrm{ACE}$ MQD Instrument (Beckman Coulter) equipped with laser induced fluorescence detection at the same conditions as described in Alvarez et al. [34].

\subsection{Circular dichroism spectroscopy (CD) and thermal denaturation}

Circular dichroism spectroscopy and thermal denaturation were performed according to Mandelli et al. [35]. Far-UV CD spectra were recorded using the JASCO 815 spectropolarimeter (JASCO Inc., Tokyo, Japan), equipped with a Peltier temperature control unit, from 195 to $260 \mathrm{~nm}$ in a $1 \mathrm{~mm}$ path length quartz cuvette. Data collection considered a scanning speed of $100 \mathrm{~nm} \mathrm{~min}-1$, spectral bandwidth of $1 \mathrm{~nm}$ and a response time of $0.5 \mathrm{~s}$. The purified enzyme $\left(0.2 \mathrm{mg} \mathrm{mL}^{-1}\right)$, diluted in $20 \mathrm{mM}$ of sodium phosphate buffer ( $\mathrm{pH} 7.4$ ) containing $50 \mathrm{mM} \mathrm{NaCl}$, was used for collection of spectral data. Solvent spectra were subtracted in all experiments, and each spectrum was an average of 20 scans. Thermal denaturation analyzes of the recombinant enzyme were monitored by measuring the ellipticity changes at $219 \mathrm{~nm}$ while increasing the temperatures from 20 to $100^{\circ} \mathrm{C}$ at a rate of $1^{\circ} \mathrm{Cmin}^{-1}$. Residual activity was measured by recovering of protein sample from the cuvette followed by incubation for $30 \mathrm{~min}$ at optimal conditions in oat $\beta$-glucan $0.25 \%$ $(\mathrm{w} / \mathrm{v})$.

\subsection{Small-angle $X$-ray scattering}

SAXS (Small angle X-ray scattering) data were collected at the Brazilian Synchrotron Light Laboratory (LNLS - CNPEM) at the SAXS1 beamline. Scattering patterns were recorded using a Pilatus detector and the wavelength of the incident radiation was set to $\lambda=1.54 \AA$ with a sample-detector distance of $908 \mathrm{~mm}$, resulting in a scattering vector (defined by $q=4 \pi \sin (\theta) / \lambda$, where $2 \theta$ is the scattering angle) ranging from $0.012<\mathrm{q}<0.436 \AA^{-1}$. SAXS analyzes were performed at $20^{\circ} \mathrm{C}$, with enzyme concentrations varying from $1.0 \mathrm{mg} \mathrm{mL}^{-1}$ to $2.4 \mathrm{mg} \mathrm{mL}^{-1}$ in the absence and presence of $5 \mathrm{mM}$ of $\mathrm{CaCl}_{2}$. SAXS data were scaled by the intensity of the beam and sample absorption. The background scattering was subtracted from the sample scattering and integration of the SAXS patterns was performed using the Fit2D software [36].

Fitting of the experimental curve and evaluation of the pairdistance distribution function $p(r)$ were conducted using the Gnom software [37] from the ATSAS package. The low-resolution dummy atom model (DAM) was generated using the $a b$ initio routine implemented in the program Dammin [38]. The molecular weight and oligomerization state were evaluated using SaxsMoW [39]. High-resolution homologous models were generated from the sequence using the Swiss-Model [40], based on the templates PDB id 1VRX and 2DPK, respectively for catalytic and Calx-beta domains. The rigid body model (RBM) was generated using Bunch [41]. Crysol [42] was used to simulate the scattering pattern and to evaluate the structural parameters of the DAM and RBM. The DAM and RBM were superimposed using the program SUPCOMB [43].

\section{Results and discussion}

\subsection{Phylogenetic analysis of CelE2}

After functional screening of a metagenomic library derived from soil, a clone harboring an insert of approximately $2.3 \mathrm{~kb}$ with the ability to hydrolyze CMC was isolated. Sequence analysis of the insert resulted in identification of a CDS for a protein with 477 amino acids, referred to as CelE2, with no putative signal peptide. Comparison of the predicted protein sequencing with the NCBI-nr database indicated high identity values to a hypothetical protein from Mycobacterium sp. EPa45 (81\% identity, accession number WP_052960145.1), glycoside hydrolase family 5 from Mycobacterium rhodesiae JS60 (79\% identity, accession number EHB55226.1) and a hypothetical protein from Mycobacterium rhodesiae (79\% identity, accession number WP_050950473.1).

The domain architecture evaluation performed by comparison of the CelE2 protein sequence to the Pfam database indicated the presence of a conserved domain from glycoside hydrolase family 5 (PF00150) in the N-terminal region, extending from amino acid 29-348 (e-value $1.5 \mathrm{e}^{-57}, 100 \%$ coverage of HMM model), while in the C-terminal region, a Calx-beta domain was predicted from amino acid 360-454 (PF03160, e-value $2.9 \mathrm{e}^{-20}, 89 \%$ coverage of HMM model). The same domain was predicted in the C-terminal end, from amino acid 350-454, when the analysis was performed against the SMART database (e-value $2.16 \mathrm{e}^{-15}$ ). The Calx-beta motif was first reported in 1997 by Schwarz and Benzer [44] as a component of the Na-Ca exchanger from Drosophila melanogaster, also identified in mammalian integrin $\beta 4$ and in proteins from Synechocystis sp. PCC6803 [44,45]. A recent search (July, 2016) for the term "Calx-beta" associated with the term "glycoside-hydrolase" in the Uniprot database [46] resulted in the identification of 251 entries. Maekawa et al. [18] and Hayase et al. [19] provided insights on the existence and importance of the Calx-beta domain in the $\beta$-glucosidase (GH3), BglM1, from Physarum polycephalum, suggesting that it may play a role in maintaining the protein tertiary structure.

Regarding the orthologous group annotation, the best classification of CelE2 (e-value $3.71 \mathrm{e}^{-169}$, score 566.5) was to ENOG4106R7G which referred to the category of carbohydrate transport and metabolism and was annotated as glycoside hydrolase family 5 . The phylogenetic tree (Fig. 1) indicated a close association of CelE2 to endoglucanases from Mycobacterium flavescens and Mycobacterium vanbaalenii (Taxon IDs: 350054 and 350058, respectively), with both harboring Calx-beta domains according to the Pfam annotation.

Recombinant CelE2 was successfully overexpressed in the cytoplasmic fraction of the E.coli Rosetta-gami2 strain and displayed a high level of purity after two protein purification steps, as indicated by SDS-PAGE (Fig. 2), with an apparent molecular weight similar to the predicted value of $53.8 \mathrm{kDa}$. 


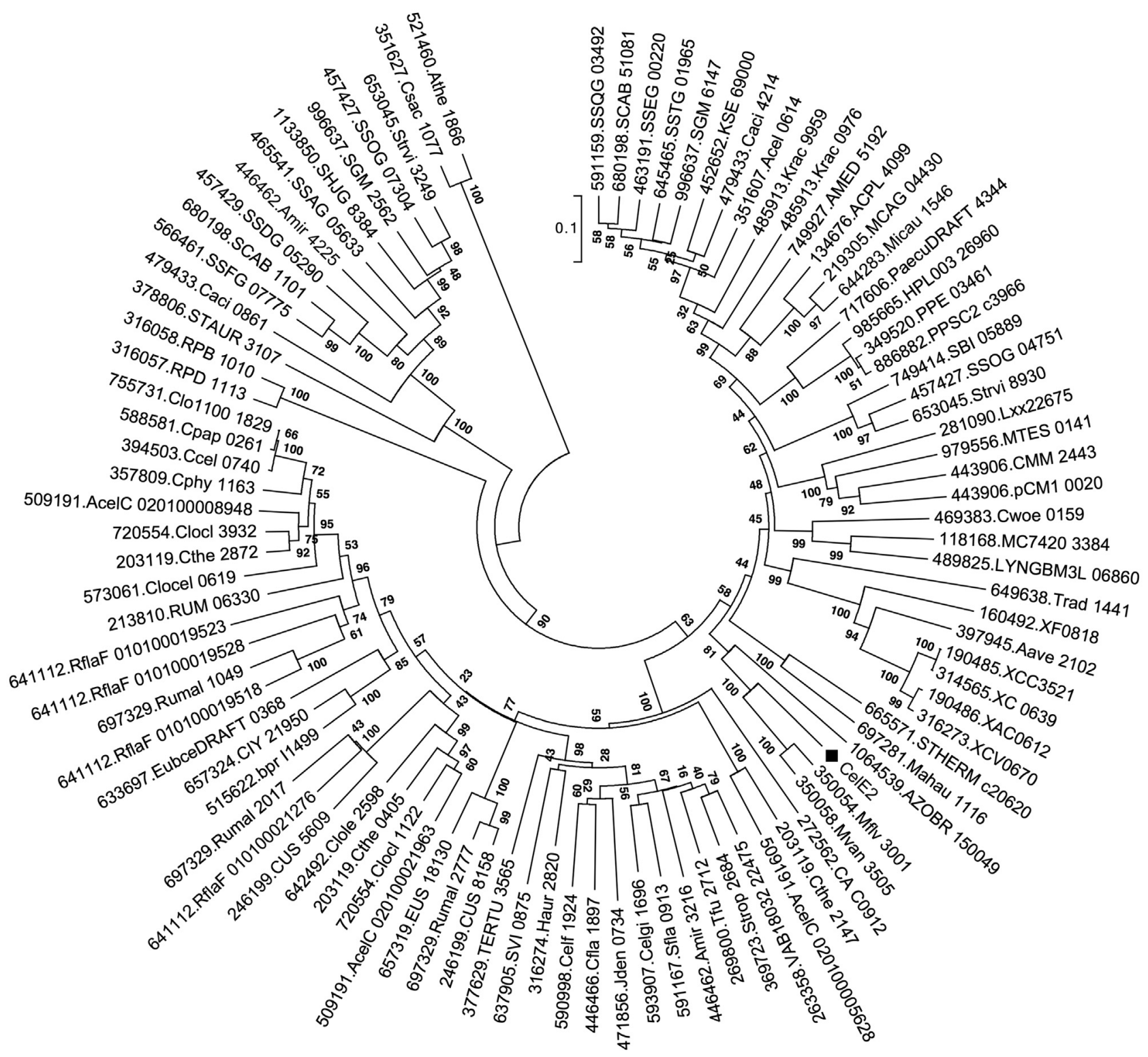

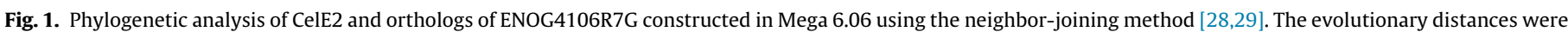

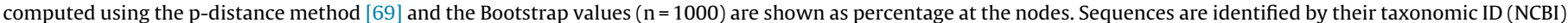
followed by gene name from the Uniprot Database [46].

\subsection{Biochemical properties, substrate specificity and thermal denaturation}

CelE2 displayed a notably preference for hydrolysis of oat $\beta$-glucan (10.0 $\pm 0.95 \mu \mathrm{mol} / \mathrm{min} / \mathrm{mg}$ - relative activity $100 \%)$, followed by lichenan $(3.6 \pm 0.06 \mu \mathrm{mol} / \mathrm{min} / \mathrm{mg}$ - relative activity $35.9 \pm 3.9 \%)$ and $\mathrm{CMC}(0.7 \pm 0.30 \mu \mathrm{mol} / \mathrm{min} / \mathrm{mg}$ - relative activity $6.6 \pm 2.8 \%$ ) (Fig. $3 \mathrm{~A}$ ). Both oat $\beta$-glucan and lichenan are mixed $\beta$ 1,3-1,4-glucans, however, in the case of lichenan there is a higher proportion of $\beta-1,3$ linkages $[47,48]$. In the other substrates tested composed of a variety of glycosidic bond types and monomeric units, lower levels or lack of enzymatic activity were observed (Fig. 3A). Specifically, the inability to cleave curdlan, a $\beta$-1,3-glucan polysaccharide, suggested that CelE2 is not able to cleave $\beta-1,3$ glycosidic bonds. Thus, the activity of CelE2 on both oat $\beta$-glucan and lichenan may be the result of hydrolysis of $\beta-1,4$ glycosidic bonds.

The evaluation of optimum temperature and $\mathrm{pH}$ using oat $\beta$ glucan as substrate revealed optimum values at $45^{\circ} \mathrm{C}$ and $\mathrm{pH} 5.3$ (Fig. 3B and C). From $15^{\circ} \mathrm{C}$ to $45^{\circ} \mathrm{C}$, CelE2 activity exhibited a cres- cent profile as a function of temperature increase, with a maximum at $45^{\circ} \mathrm{C}$. At $50^{\circ} \mathrm{C}$, CelE2 was able to retain approximately $82 \%$ of its maximum enzymatic activity; however, from 50 to $55^{\circ} \mathrm{C}$ there was a drastic decrease in enzymatic activity to approximately $39 \%$. Optimum temperature values of approximately $50^{\circ} \mathrm{C}$ have already been reported for other soil metagenome derived cellulases [20,49]. At $\mathrm{pH}$ values ranging from 4.8 and 5.6, CelE2 showed relative activity values greater than $55 \%$, with the optimum at $\mathrm{pH}$ 5.3. This result indicated an acidophilic characteristic of CelE2, which is a common behavior in comparison to other cellulases derived from soil metagenome [49,50].

CelE2 exhibited considerable thermal stability (Fig. 3D) at $40{ }^{\circ} \mathrm{C}$ after $360 \mathrm{~min}$, retaining approximately $68 \%$ of its initial enzymatic activity. After $360 \mathrm{~min}$ of incubation at $50^{\circ} \mathrm{C}$ and $60^{\circ} \mathrm{C}$, CelE2 was able to retain $38 \%$ and $20 \%$ of its enzymatic activity, respectively. CelE2 was virtually inactivated after $180 \mathrm{~min}$ of incubation at $70^{\circ} \mathrm{C}$. At higher temperatures, $90^{\circ} \mathrm{C}$ and $80^{\circ} \mathrm{C}$, CelE2 was able to maintain approximately $18 \%$ and $57 \%$ of its activity, respectively, after $30 \mathrm{~min}$ of incubation. 


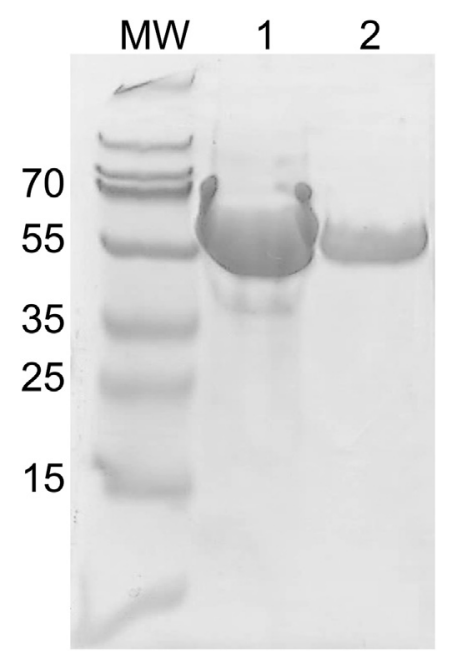

Fig. 2. SDS-PAGE of recombinant CelE2 protein purification performed first by affinity chromatography (column 1 ) followed by gel filtration chromatography (column 2). MW - Molecular weight marker (PageRuler Plus Prestained Protein Ladder 10-250 kDa, Thermo Scientific).

Thermal unfolding was assessed by circular dichroism spectroscopy. Firstly, the CelE2 far-UV CD spectra resulted in a profile with negative bands around 209 and $219 \mathrm{~nm}$ and a positive band around $190 \mathrm{~nm}$ (Fig. 4A), reveling a secondary structure consistent with alpha-beta proteins [51], which is similar to the profile of others members of the GH5 family [20,52,53]. Thermal denaturation of CelE2 was evaluated by analysis of temperature-induced changes in the $C D$ signals at $219 \mathrm{~nm}$. The melting temperature (Tm) estimated via sigmoidal fitting of these data for CelE2 was $50^{\circ} \mathrm{C}$ (Fig. 4B), which is consistent with the activity assays (Fig. 3D), since at higher temperatures the enzyme showed progressive loss of enzymatic activity over time. Interestingly, when incubated at $99^{\circ} \mathrm{C}$ for $15 \mathrm{~min}$, CelE2 did not lose its secondary structure (Fig. 4A) nor its activity (residual relative activity of approximately 26\%), which explains the activity observed at $90^{\circ} \mathrm{C}$ during approximately 30 min, as shown in Fig. 3D. However, when CelE2 was progressively heated (from 20 to $100^{\circ} \mathrm{C}$ at a rate of $1^{\circ} \mathrm{C} \mathrm{min}^{-1}$ ), it lost its secondary structure and was inactivated, as assessed by enzymatic reactions (relative activity of $0.8 \%$ ).

\subsection{Effect of metallic compounds, EDTA and surfactants on CelE2 activity}

As shown in Fig. $5 \mathrm{~A}$, apart from $\mathrm{CaCl}_{2}$ and $\mathrm{CoCl}_{2}$, all metallic salts evaluated resulted in varying degrees of inhibition to CelE2 enzymatic activity. Based on results described in literature, the effect of metal ions on endoglucanase activity is highly variable, however, inhibition by $\mathrm{Cu}^{2+}, \mathrm{Fe}^{3+}, \mathrm{Fe}^{2+}$ and $\mathrm{Zn}^{2+}$ have already been reported [54-60].

While $5 \mathrm{mM}$ of $\mathrm{CoCl}_{2}$ did not show a clear effect on enzymatic activity, the addition of $5 \mathrm{mM}$ of $\mathrm{CaCl}_{2}$ promoted an increase in CelE2 enzymatic activity. The effect of calcium on CelE2 enzymatic activity was further evaluated, first by the treatment of a diluted sample of CelE2 with three different concentrations of EDTA ( $1 \mathrm{mM}, 5 \mathrm{mM}$ and $10 \mathrm{mM}$ ). As shown in Fig. 5B, treatment with $5 \mathrm{mM}$ and $10 \mathrm{mM}$ promoted a significant reduction in CelE2 activity ( $\mathrm{p}$-value $<0.05$ ), suggesting that CelE2 activity is influenced by the presence of divalent cations even without external metal ions supplementation. Interestingly, the addition of $5 \mathrm{mM}$ of $\mathrm{CaCl}_{2}$ to
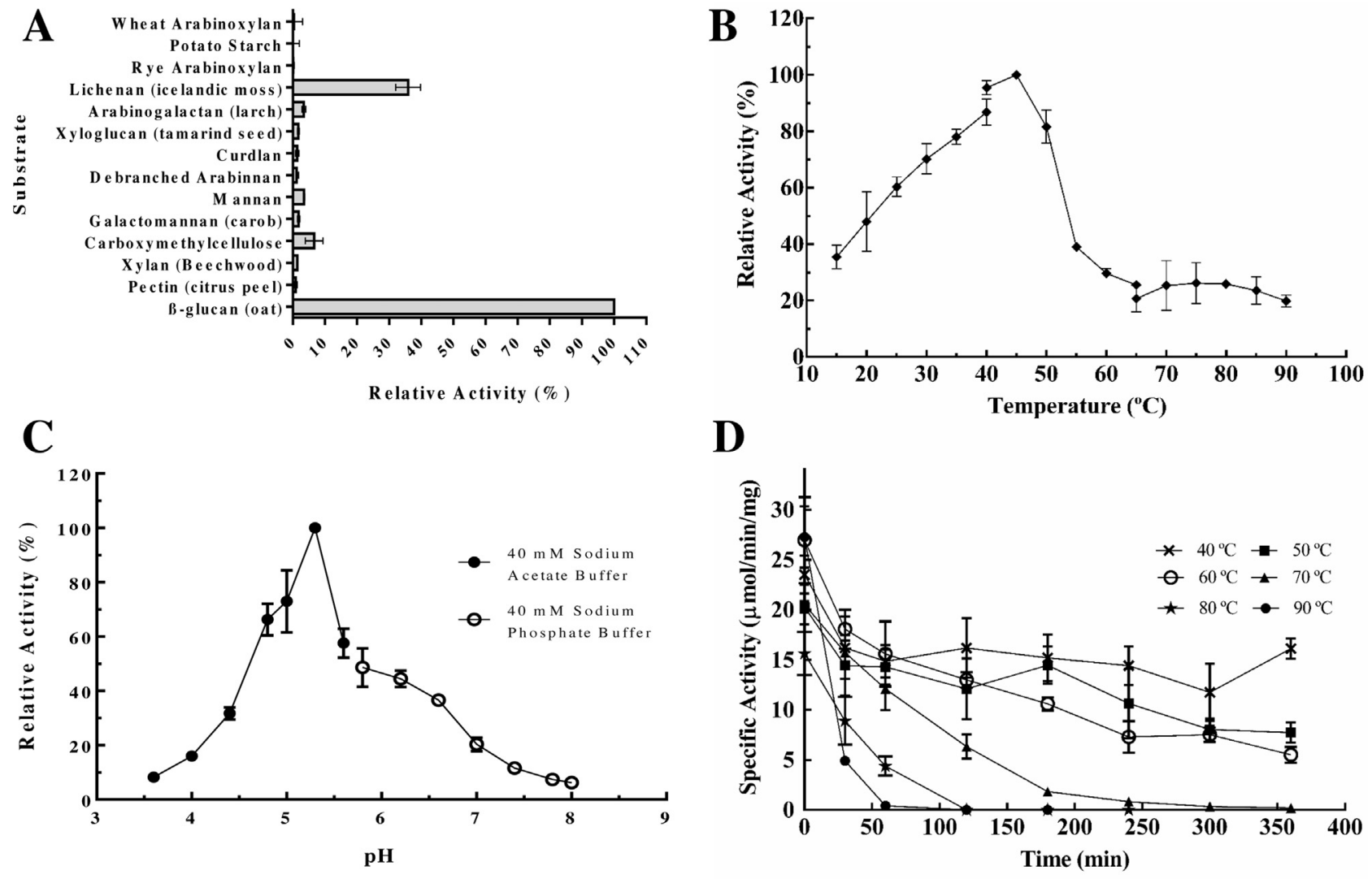

International Journal of Biological Macromolecules. Pimentel et al., 2016. FIG. 3.

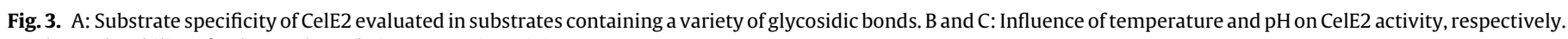
D: Thermal stability of CelE2 evaluated via enzymatic activity. 

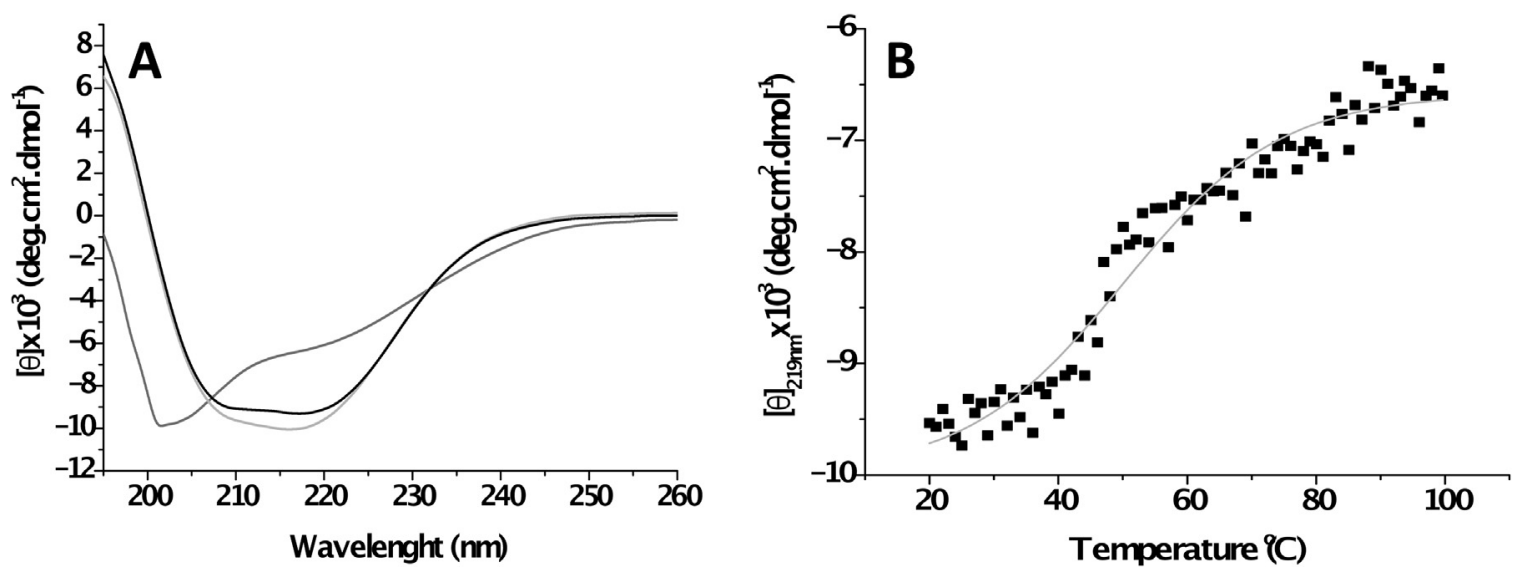

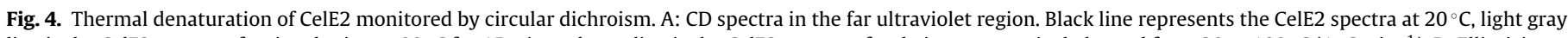

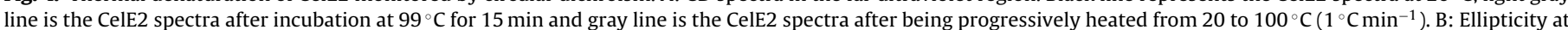

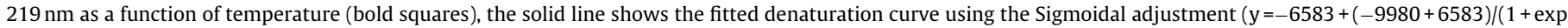
$((\mathrm{x}-50) / 12))$ with R-squared of 0.96).

A

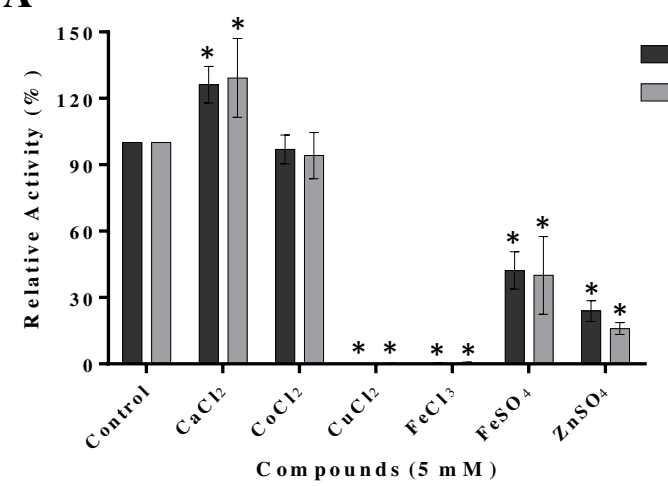

B

Experiment 1 Experiment 2

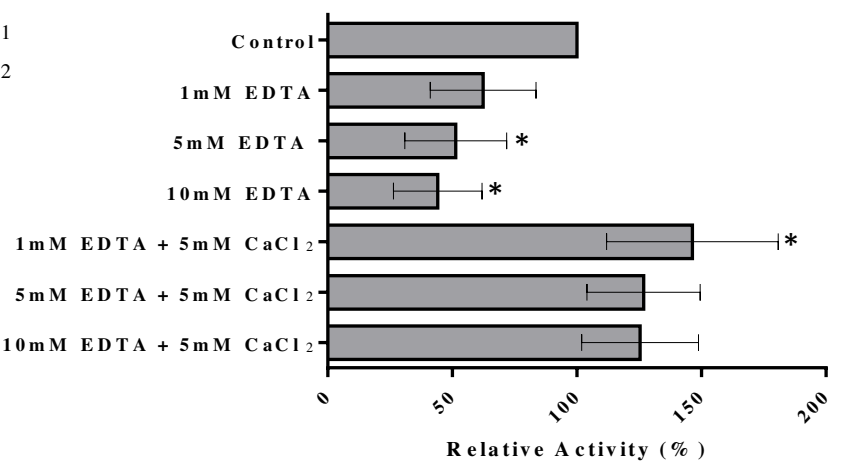

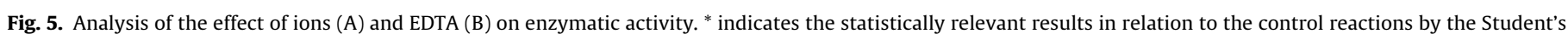
$t$-test with p-value $<0.05$.

reactions containing the EDTA-treated enzyme was able to restore CelE2 activity (Fig. 5B). In a study performed with an endoglucanase from $B$. succinogenes (EG1), the presence of $1 \mathrm{mM}$ EDTA decreased enzymatic activity, but the addition of $1 \mathrm{mM} \mathrm{CaCl}_{2}$ was not able to completely restore enzyme activity [54]. On the other hand, Liu et al., 2011 reported a soil metagenome derived endoglucanase which presented approximately a $24 \%$ improvement on enzymatic activity in the presence of $\mathrm{CaCl}_{2}$, although the treatment with 10 Mm EDTA showed only a $7 \%$ reduction in activity [50]. These results suggest that CelE2 enzymatic activity may be modulated in the presence of $\mathrm{CaCl}_{2}$.

Regarding the influence of the surfactants, Triton $\mathrm{X}-100$ reduced CelE2 activity by approximately $26 \%( \pm 8 \%)$ while SDS completely inactivated the enzyme. Interestingly, the addition of $5 \mathrm{mM} \mathrm{CaCl}_{2}$ to the reactions with surfactants resulted in less susceptibility of CelE2 to these compounds, since CelE2 was able to retain around $98 \%( \pm 2 \%)$ and $7 \%( \pm 3 \%)$ of its enzymatic activity in Triton X-100 and SDS, respectively. Altogether, these results indicated that the presence of $\mathrm{CaCl}_{2}$ may have an important influence on CelE2 activity.

\subsection{CelE2 displayed beta-1,4 endoglucanase behavior with evidences of transglycosilation activity}

Capillary zone electrophoresis was used as a tool to characterize the cleavage pattern of CelE2. Degradation of oat $\beta$-glucan gener- ated mainly di-, tri-, tetra- and pentasaccharides (Fig. 6A), while degradation of Avicel (Fig. 6A) resulted in accumulation of mainly di- and trisaccharides. Therefore, CelE2 displayed a behavior typical of endoglucanases, which randomly attack the polysaccharide chain resulting in the formation of oligosaccharides with a wide range of length [61].

Also, the cleavage pattern of CelE2 was analyzed by the products released from hydrolysis of cellooligosaccharides. CelE2 was able to cleave C5 and C4 (Fig. 6B), but not C3 and C2 (data not shown), suggesting that the minimal length of the glucan chain to be cleaved is four glucose units. Regarding hydrolysis of C4, it was observed an accumulation of di- and trisaccharides. However, hypothesizing that CelE2 would be able to cleave an external glycosidic bond of C4 to form C3, it should result in the release of glucose, which was not observed. The same occurred in the hydrolysis of $\mathrm{C} 5$ which generated tetra-, tri- and disaccharides, with no clear evidence of glucose release. In addition, in both cases there were evidences of formation of products with higher degree of polymerization than the substrates initially added (Fig. 6B). Together, these two results suggested the occurrence of transglycosylation activity, which is a characteristic displayed by many retaining glycoside hydrolases [62], which is the mechanism exhibited by GH5 members [11]. Several members from the GH5 family were already described as possessing transglycosylation activity [63-65], however, accordingly to Aspeborg et al. [12], the transglycosylation activity does not correlate with subfamily classification and may be related to subtle peculiarities in protein structure. 


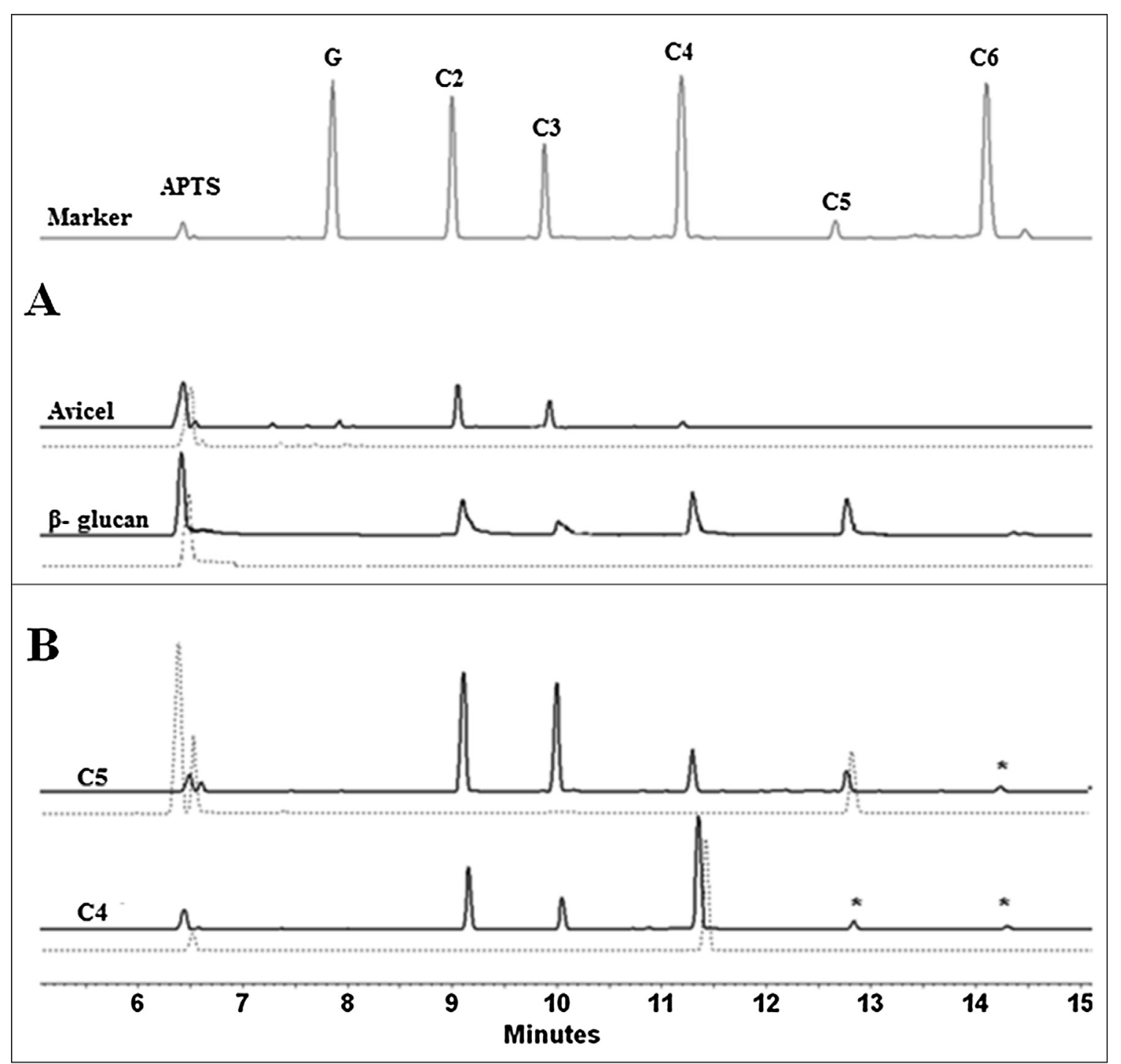

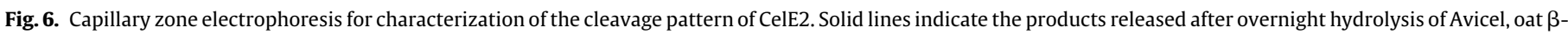

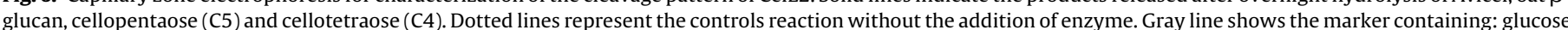

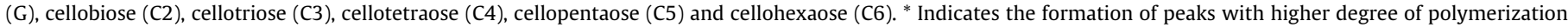
than the oligosaccharide initially added to the reaction. APTS indicates excess of the fluorescent label 9-Aminopyrene-1,4,6-trisulfonic acid trisodium salt .

\subsection{Small-angle $X$-ray scattering}

In order to obtain the low-resolution envelope of CelE2 and investigate the effect of calcium ions on enzyme stability, SAXS data were collected in the presence and absence of $5 \mathrm{mM}$ of $\mathrm{CaCl}_{2}$. Since no interparticle correlation effect was detected, analyzes were conducted using data at the higher protein concentration $\left(2.4 \mathrm{mg} \mathrm{mL}^{-1}\right.$ in the presence and $2.0 \mathrm{mg} \mathrm{mL}^{-1}$ in the absence of calcium), due to better statistical results. Fig. 7 shows the experimental data for CelE2 in the presence and absence of $\mathrm{CaCl}_{2}$. The zoom to the rectangle in the low angle region (Fig. 7A - Insert) reveals that the enzyme has a larger tendency to aggregate in the absence of calcium, indicated by the ascent of the data points in this region. The radius of gyration $\left(R_{g}\right)$ obtained by Guinier approximation (Fig. 7B) respected the q. $R_{\mathrm{g}}<1.3 \mathrm{limit}$ [66]. $\mathrm{R}_{\mathrm{g}}$ obtained in the presence of calcium (31.1 $\AA$ ) had a significant decrease compared to data without calcium ions (35.1 $\AA$ ), quantitatively demonstrating the aggregation. Guinier analysis showed that calcium ions provide CelE2 with greater stability.
Homologous models from the (1) catalytic domain was generated based on the crystallography structure of an endocellulase from Acidothermus cellulolyticus [67] (PDB id: 1VRX), which presents a sequence identity of $53.91 \%$, and from the (2) Calx-beta domain was generated based on the crystallography structure of a sodium/calcium exchanger from Canis lupus [68] (PDB id: 2DPK), which presents a sequence identity of $59.02 \%$.

Fitting of the experimental data and evaluation of the $p(r)$ (Fig. 8-Insert) were conducted for data in the presence of $\mathrm{CaCl}_{2}$ due to the higher stability. The low-resolution dummy atom model was generated and compared with the rigid-body model, which was generated based on the relative positions between the domains, compared to the experimental data. Fig. 8 shows the fits against the SAXS experimental pattern. Structural parameters from the experimental SAXS data of CelE2 and simulated SAXS from the DAM and the RBM are presented in Table 1.

The molecular weight evaluated from SAXSMoW (67.4kDa) compared with the theoretical value $(53.8 \mathrm{kDa})$ shows that, in the experimental conditions CelE2 behaves mainly as a monomer in solution. However, the parameters reveal a tendency of CelE2 to 
$\mathbf{A}$

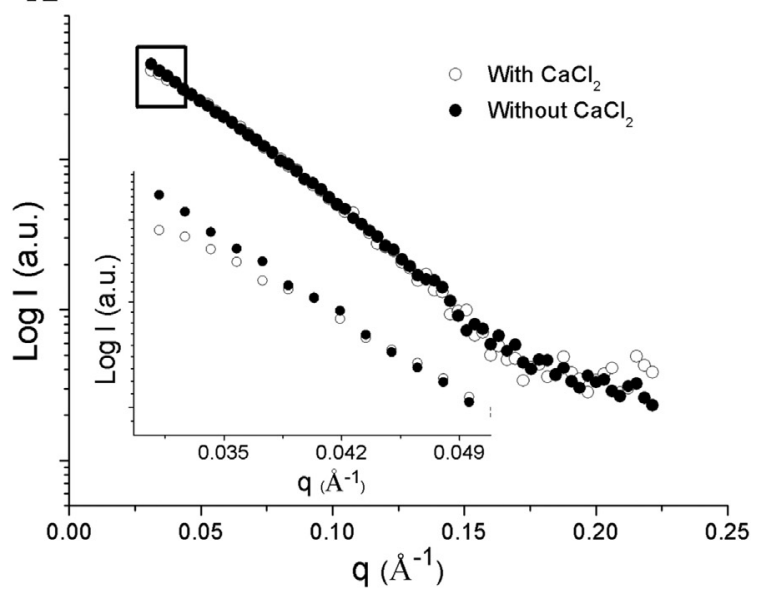

B

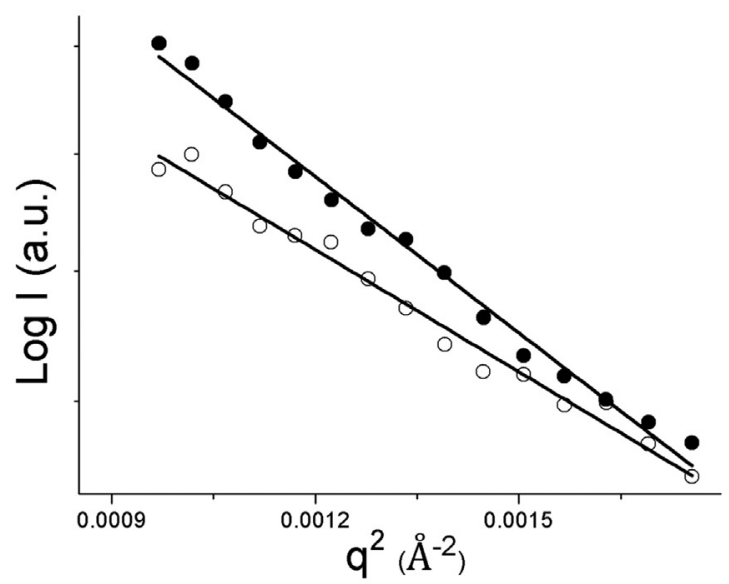

International Journal of Biological Macromolecules. Pimentel et al., 2016. FIG. 7.

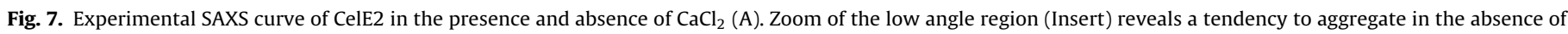
$\mathrm{CaCl}_{2}$. Guinier Approximation (B).

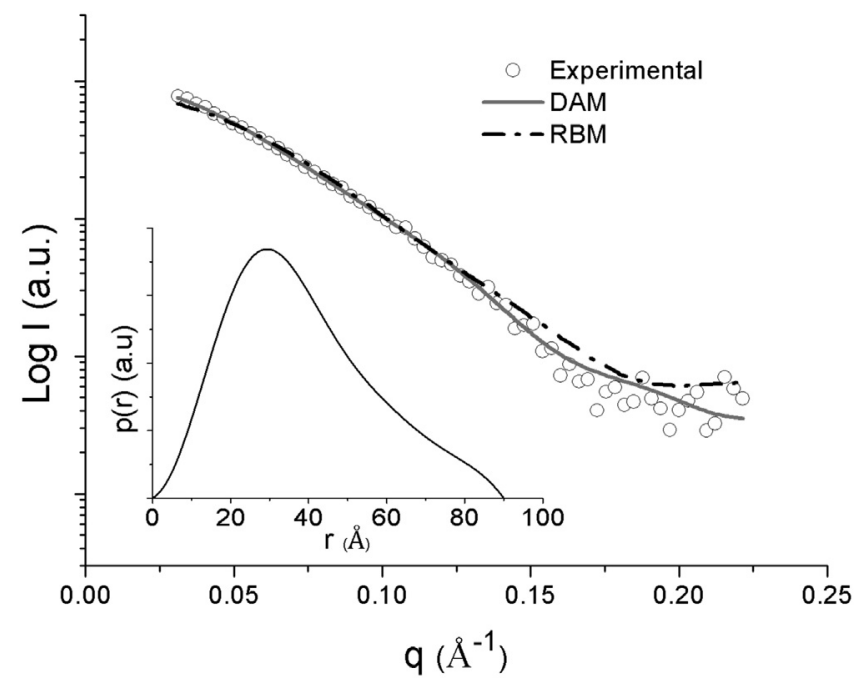

Fig. 8. Experimental data of CelE2 in the presence of $5 \mathrm{mM}$ of $\mathrm{CaCl}_{2}$ and fitting procedures (DAM: Dummy atoms model; RBM: Rigid-body model). Pair-distance distribution function $\mathrm{p}(\mathrm{r})$ (Insert).

Table 1

SAXS structural parameters of CelE2. ${ }^{1}$ Exp, calculated from the experimental data in the presence of $\mathrm{CaCl}_{2 .} .{ }^{2} \mathrm{DAM}$, parameters of the dummy atoms model. ${ }^{3} \mathrm{RBM}$, parameters of the rigid-body model. ${ }^{4}$ Resolution is calculated as $2 \pi / \mathrm{q}_{\max }$.

\begin{tabular}{|c|c|c|c|}
\hline Parameters & $\operatorname{Exp}^{1}$ & $\mathrm{DAM}^{2}$ & $\mathrm{RBM}^{3}$ \\
\hline $\mathrm{R}_{\mathrm{g}}(\hat{A})$ (Guinier) & 31.1 & - & - \\
\hline $\mathrm{R}_{\mathrm{g}}(\hat{\AA})$ & 29.7 & 29.3 & 25.0 \\
\hline $\mathrm{D}_{\max }(\hat{A})$ & 90.0 & 91.2 & 82.1 \\
\hline SAXS resolution ${ }^{4}(\AA ́)$ & 28.4 & - & - \\
\hline Molecular weight (kDa) & 67.4 & - & - \\
\hline$x^{2}$ & - & 3.5 & 4.7 \\
\hline
\end{tabular}

form oligomers, indicated by the higher molecular weight values evaluated from SAXS and increase in the $\mathrm{R}_{\mathrm{g}}$ parameter when evaluated only in the low $q$ region. Nevertheless, this tendency is so small that it does not influence the reliability of the results, as shown in the good agreement of the models (Fig. 9).

\section{Concluding remarks}

The cellulase (GH5) CelE2, displaying an unconventional domain architecture, was successfully heterologously expressed in E.coli, purified and submitted to biochemical characterization. CelE2 exhibited mesophilic and acidic characteristics, with substrate preference for mixed $\beta-1,3-1,4$-glucans and a typical cleavage pattern of endoglucanase with evidences of transglycosylation activity. The addition of $\mathrm{CaCl}_{2}$ was able to not only promote an increase in CelE2 activity but also resulted in less susceptibility of inactivation in the presence of surfactants. SAXS experiments provided key information regarding the increased stability of the enzyme in the presence of $\mathrm{CaCl}_{2}$, which possibly explains the higher activity observed in the presence of this compound. Influence of the Calx-beta domain on cellulase activity is a key point to be elucidated, especially considering that this domain has already been identified in other glycoside hydrolases.

\section{Author contributions}

Conceived and designed the experiments: AGP, TMA, FMS, MVL. Performed the experiments: ACP, TMA, GCGE, FM, RT, CAG, MON. Analyzed the data: ACP, TMA, FM, CAG, MON, DAAP, FMS, JPLFC. Wrote the paper: ACP, TMA, FMS, FM, RT, MVL, JPLFC, CAG, MON.

\section{Acknowledgments}

The authors would like to acknowledge the São Paulo Research Foundation (grant \#2008/58037-9, grant \#2014/06923-6, grant \#2010/11469-1, grant \#2014/12861-3, grant \#2016/01926-2, and grant \#2014/04105-4, São Paulo Research Foundation (FAPESP)) and National Council for Scientific and Technological Development - CNPq, Brazil (CNPq: grant \#448854/2014-7, grant \#310186/20145, grant \#442333/2014-5 and grant \#132372/2016-9) for financial their support. We would like to acknowledge the Brazilian Synchrotron Light Laboratory (LNLS - CNPEM) for the SAXS1 beamline facilities, LAM (Laboratory of Macromolecule Analysis, CTBE/CNPEM) and NGS (High Throughput Sequencing and Robotics Laboratory, CTBE/CNPEM) facilities and the Brazilian Bioethanol Science and Technology Laboratory (CTBE/CNPEM) for the technical support. 

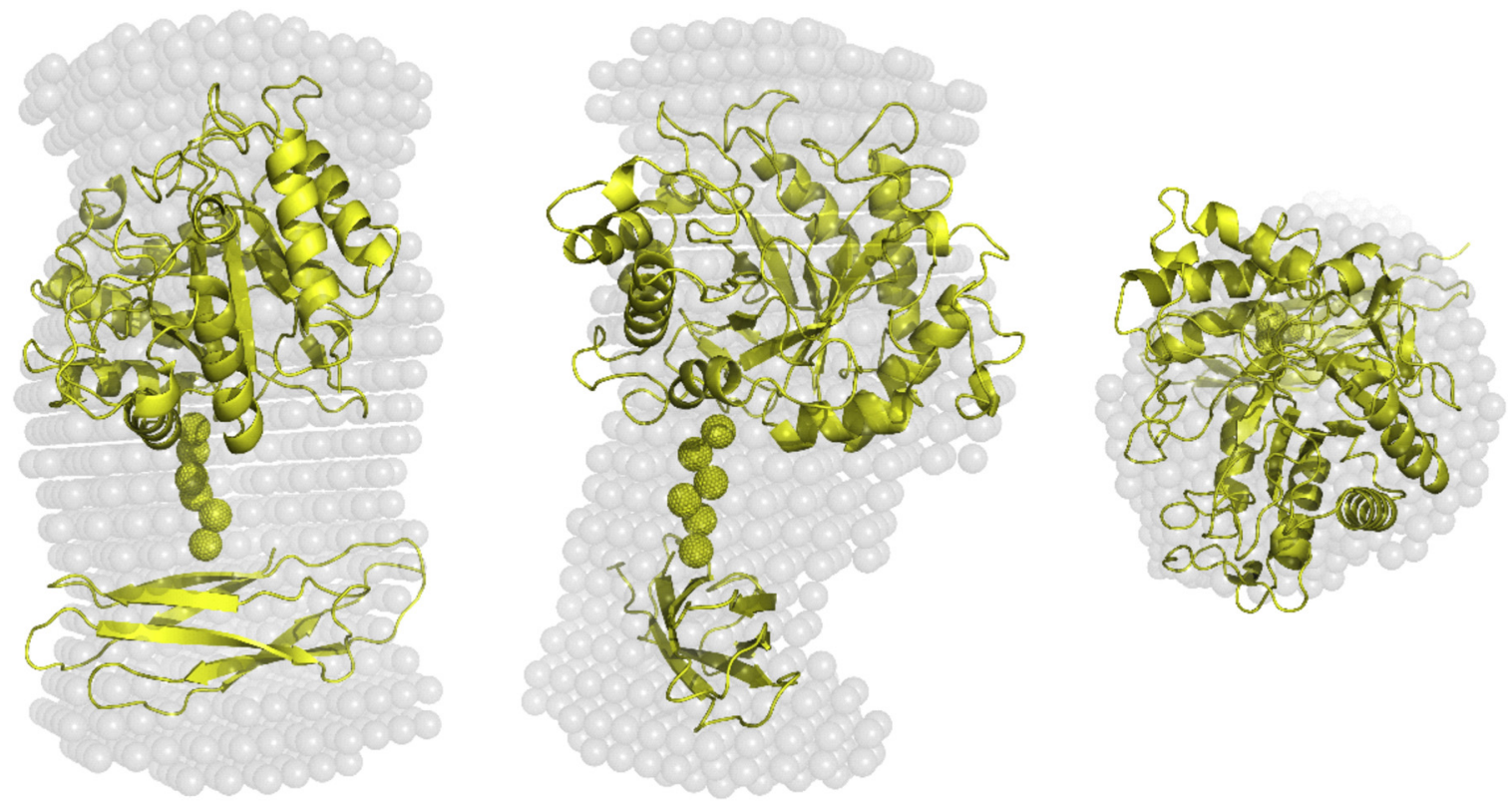

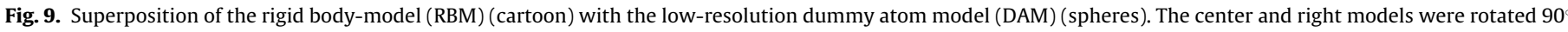
around the $\mathrm{y}$ - axis and $90^{\circ}$ around the $\mathrm{x}$-axis from the orientation shown on the left panel.

\section{References}

[1] P. Dwivedi, J.R.R. Alavalapati, P. Lal, Cellulosic ethanol production in the United States: conversion technologies, current production status, economics, and emerging developments, Energy Sustain. Dev. 13 (2009) 174-182.

[2] M.E. Himmel, S.-Y. Ding, D.K. Johnson, W.S. Adney, M.R. Nimlos, J.W. Brady, T.D. Foust, Biomass recalcitrance: engineering plants and enzymes for biofuels production, Science 315 (2007) 804-807.

[3] D.M. Alonso, J.Q. Bond, J.A. Dumesic, Catalytic conversion of biomass to biofuels, Green Chem. 12 (2010) 1493-1513.

[4] C.N. Hamelinck, G. Van Hooijdonk, a. P.C. Faaij, Ethanol from lignocellulosic biomass: techno-economic performance in short-, middle- and long-term, Biomass Bioenergy 28 (2005) 384-410.

[5] A.T.W.M. Hendriks, G. Zeeman, Pretreatments to enhance the digestibility of lignocellulosic biomass, Bioresour. Technol. 100 (2009) 10-18.

[6] B. Yang, Z. Dai, S.-Y. Ding, C.E. Wyman, Enzymatic hydrolysis of cellulosic biomass, Biofuels 2 (2011) 421-450.

[7] F. Segato, A.R.L. Damásio, R.C. de Lucas, F.M. Squina, R.A. Prade, Genomics review of holocellulose deconstruction by aspergilli, Microbiol. Mol. Biol. Rev. 78 (2014) 588-613.

[8] J.P.L. Franco Cairo, L.C. Oliveira, C.A. Uchima, T.M. Alvarez, A.P. da, S. Citadini, J. Cota, F.C. Leonardo, A.M. Costa-Leonardo, M.F. Carazzolle, F.F. Costa, G.A.G. Pereira, F.M. Squina, Deciphering the synergism of endogenous glycoside hydrolase families 1 and 9 from Coptotermes gestroi, Insect Biochem. Mol. Biol. 43 (2013) 970-981.

[9] S.J. Horn, G. Vaaje-Kolstad, B. Westereng, V.G. Eijsink, Novel enzymes for the degradation of cellulose, Biotechnol. Biofuels. 5 (2012) 45.

[10] T.L.R. Corrêa, L.V. dos Santos, G.A.G. Pereira, AA9 and AA10: from enigmatic to essential enzymes, Appl. Microbiol. Biotechnol. 100 (2016) 9-16.

[11] V. Lombard, H. Golaconda Ramulu, E. Drula, P.M. Coutinho, B. Henrissat, The carbohydrate-active enzymes database (CAZy) in 2013, Nucleic Acids Res. 42 (2014) D490-D495.

[12] H. Aspeborg, P.M. Coutinho, Y. Wang, H. Brumer, B. Henrissat, Evolution, substrate specificity and subfamily classification of glycoside hydrolase family 5 (GH5), BMC Evol. Biol. 12 (2012) 186.

[13] Z. Chen, G.D. Friedland, J.H. Pereira, S. a. Reveco, R. Chan, J.I. Park, M.P. Thelen, P.D. Adams, A.P. Arkin, J.D. Keasling, H.W. Blanch, B. a. Simmons, K.L. Sale, D. Chivian, S.R. Chhabra, Tracing determinants of dual substrate specificity in glycoside hydrolase family 5, J. Biol. Chem. 287 (2012) 25335-25343.

[14] F.M. Medie, G.J. Davies, M. Drancourt, B. Henrissat, Genome analyses highlight the different biological roles of cellulases, Nat. Rev. Microbiol. 10 (2012) 227-234

[15] A.B. Boraston, D.N. Bolam, H.J. Gilbert, G.J. Davies, Carbohydrate-binding modules: fine-tuning polysaccharide recognition, Biochem. J. 382 (2004) 769-781.

[16] I.A. Kataeva, R.D. Seidel, A. Shah, L.T. West, X.L. Li, L.G. Ljungdahl, The fibronectin type 3-like repeat from the Clostridium thermocellum cellobiohydrolase CbHa promotes hydrolysis of cellulose by modifying its surface, Appl. Environ. Microbiol. 68 (2002) 4292-4300.
[17] H. Liu, J.H. Pereira, P.D. Adams, R. Sapra, B.A. Simmons, K.L. Sale, Molecular simulations provide new insights into the role of the accessory immunoglobulin-like domain of Cel9A, FEBS Lett. 584 (2010) 3431-3435.

[18] A. Maekawa, M. Hayase, T. Yubisui, Y. Minami, A cDNA cloned from Physarum polycephalum encodes new type of family 3 beta-glucosidase that is a fusion protein containing a calx-beta motif, Int. J. Biochem. Cell Biol. 38 (2006) 2164-2172.

[19] M. Hayase, A. Maekawa, T. Yubisui, Y. Minami, Properties intracellular localization, and stage-specific expression of membrane-bound beta-glucosidase, BglM1, from Physarum polycephalum, Int. J. Biochem. Cell Biol. 40 (2008) 2141-2150

[20] T.M. Alvarez, J.H. Paiva, D.M. Ruiz, J.P.L.F. Cairo, I.O. Pereira, D.A.A. Paixão, R.F. De Almeida, C.C.C. Tonoli, R. Ruller, C.R. Santos, F.M. Squina, M.T. Murakami, Structure and function of a novel cellulase 5 from sugarcane soil metagenome, PLoS One 8 (2013) e83635.

[21] A. Kearse, M. Moir, R. Wilson, A. Stones-Havas, S. Cheung, M. Sturrock, S. Buxton, S. Cooper, A. Markowitz, S. Duran, C. Thierer, T. Ashton, B. Mentjies, P. Drummond, Geneious Basic: an integrated and extendable desktop software platform for the organization and analysis of sequence data, Bioinformatics 28 (2012) 1647-1649

[22] R.D. Finn, P. Coggill, R.Y. Eberhardt, S.R. Eddy, J. Mistry, A.L. Mitchell, S.C. Potter, M. Punta, M. Qureshi, A. Sangrador-Vegas, G.A. Salazar, J. Tate, A. Bateman, The Pfam protein families database: towards a more sustainable future, Nucleic Acids Res. 44 (2016) D279-D285.

[23] J. Schultz, F. Milpetz, P. Bork, C.P. Ponting, SMART a simple modular architecture research tool: identification of signaling domains, Proc. Natl. Acad. Sci. U. S. A. 95 (1998) 5857-5864

[24] I. Letunic, T. Doerks, P. Bork, SMART: Recent updates, new developments and status in 2015, Nucleic Acids Res. 43 (2015) D257-D260.

[25] T.N. Petersen, S. Brunak, G. von Heijne, H. Nielsen, SignalP 4.0: discriminating signal peptides from transmembrane regions, Nat. Methods. 8 (2011) 785-786.

[26] E. Gasteiger, C. Hoogland, A. Gattiker, S. Duvaud, M.R. Wilkins, R.D. Appel, A. Bairoch, Protein identification and analysis tools on the ExPASy server, in: J.M. Walker (Ed.), The Proteomics Protocols Handbook, Humana Press, 2005, pp. 571-607.

[27] J. Huerta-Cepas, D. Szklarczyk, K. Forslund, H. Cook, D. Heller, M.C. Walter, T. Rattei, D.R. Mende, S. Sunagawa, M. Kuhn, L.J. Jensen, C. von Mering, P. Bork, eggNOG 4.5: a hierarchical orthology framework with improved functional annotations for eukaryotic, prokaryotic and viral sequences, Nucleic Acids Res. 44 (2016) D286-D293.

[28] K. Tamura, G. Stecher, D. Peterson, A. Filipski, S. Kumar, MEGA6: Molecular evolutionary genetics analysis version 6.0, Mol. Biol. Evol. 30 (2013) 2725-2729.

[29] N. Saitou, M. Nei, The neighgbor-joining method: a new method for reconstructing phylogenetic trees, Mol. Biol. Evol. 4 (1987) 406-425.

[30] U.K. Laemmli, Cleavage of structural proteins during the assembly of the head of bacteriophage T4, Nature 227 (1970) 680-685.

[31] G.L. Miller, Use of dinitrosalicylic acid reagent for determination of reducing sugar, Anal. Chem. 31 (1959) 426-428. 
[32] X.C. Mo, C.L. Chen, H. Pang, Y. Feng, J.X. Feng, Identification and characterization of a novel xylanase derived from a rice straw degrading enrichment culture, Appl. Microbiol. Biotechnol. 87 (2010) 2137-2146.

[33] F.T.A. Evangelista, R.A. Liu, M.S. Chen, Characterization of 9-aminopyrene-1,4,6-trisulfonate derivatized sugars by capillary electrophoresis with laser-induced fluorescence detection, Anal. Chem. 67 (1995) 2239-2245.

[34] T.M. Alvarez, M.V. Liberato, J.P.L.F. Cairo, D.A.A. Paixão, B.M. Campos, M.R Ferreira, R.F. Almeida, I.O. Pereira, A. Bernardes, G.C.G. Ematsu, M. Chinaglia, I. Polikarpov, M. de Oliveira Neto, F.M. Squina, A novel member of GH16 family derived from sugarcane soil metagenome, Appl. Biochem. Biotechnol. 177 (2015) 304-317.

[35] F. Mandelli, J.P.L. Franco Cairo, A.P.S. Citadini, F. Büchli, T.M. Alvarez, R.J. Oliveira, V.B.P. Leite, A.F. Paes Leme, A.Z. Mercadante, F.M. Squina, The characterization of a thermostable and cambialistic superoxide dismutase from thermus filiformis, Lett. Appl. Microbiol. 57 (2013) 40-46.

[36] A.P. Hammersley, FIT2D: an introduction and overview, ESRF Intern. Report. 68 (1997).

[37] D.I. Svergun, Determination of the regularization parameter in indirecttransform methods using perceptual criteria, J. Appl. Crystallogr. 25 (1992) 495-503.

[38] D.I. Svergun, Restoring low resolution structure of biological macromolecules from solution scattering using simulated annealing, Biophys. J. 76 (1999) 2879-2886.

[39] H. Fischer, M. De Oliveira Neto, H.B. Napolitano, I. Polikarpov, A.F. Craievich, Determination of the molecular weight of proteins in solution from a single small-angle X-ray scattering measurement on a relative scale, J. Appl. Crystallogr. 43 (2010) 101-109.

[40] M. Biasini, S. Bienert, A. Waterhouse, K. Arnold, G. Studer, T. Schmidt, F. Kiefer, T.G. Cassarino, M. Bertoni, L. Bordoli, T. Schwede, SWISS-MODEL: Modelling protein tertiary and quaternary structure using evolutionary information, Nucleic Acids Res. 42 (2014) W252-W258.

[41] M.V. Petoukhov, D.I. Svergun, Global rigid body modeling of macromolecular complexes against small-angle scattering data, Biophys. J. 89 (2005) $1237-1250$

[42] D.I. Svergun, C. Barberato, M.H.J. Koch, CRYSOL - a program to evaluate X-ray solution scattering of biological macromolecules from atomic coordinates, J. Appl. Crystallogr. 28 (1995) 768-773.

[43] M.B. Kozin, D.I. Svergun, Automated matching of high- and low-resolution structural models, J. Appl. Crystallogr. 34 (2001) 33-41.

[44] E.M. Schwarz, S. Benzer, Calx a Na-Ca exchanger gene of Drosophila melanogaster, Proc. Natl. Acad. Sci. U. S. A. 94 (1997) 10249-10254.

[45] E. Schwarz, S. Benzer, Calx beta trend 1999, Trends Biochem. Sci. 24 (1999) 260.

[46] The UniProt Consortium, UniProt: a hub for protein information, Nucleic Acids Res. 43 (2015) D204-D212.

[47] A. Lazaridou, C.G. Biliaderis, M. Micha-Screttas, B.R. Steele, A comparative study on structure-function relations of mixed-linkage (1->3), (1->4) linear beta-D-glucans, Food Hydrocoll. 18 (2004) 837-855.

[48] P.J. Wood, J. Weisz, B.A. Blackwell, Structural studies of (1-3)(1-4)beta-D-Glucans by 13C-Nuclear magnetic resonance spectroscopy and by rapid analysis of cellulose-Like regions using high-Performance anion-Exchange chromatography of oligosaccharides released by lichenase, Cereal Chem. 71 (1994) 301-307.

[49] M. Hua, S. Zhao, L. Zhang, D. Liu, H. Xia, F. Li, S. Chen, Direct detection, cloning and characterization of a glucoside hydrolase from forest soil, Biotechnol. Lett. 37 (2015) 1227-1232.

[50] J. Liu, W.D. Liu, X.L. Zhao, W.J. Shen, H. Cao, Z.L. Cui, Cloning and functional characterization of a novel endo-beta-1 4- glucanase gene from a soil-derived metagenomic library, Appl. Microbiol. Biotechnol. 89 (2011) 1083-1092.
[51] N. Greenfield, Using circular dichroism spectra to estimate protein secondary structure, Nat. Protoc. 1 (2007) 2876-2890.

[52] F. Zheng, S. Ding, Processivity and enzymatic mode of a glycoside hydrolase family 5 endoglucanase from Volvariella volvacea, Appl. Environ. Microbiol. 79 (2013) 989-996.

[53] C.R. dos Santos, J.H. Paiva, A.N. Meza, J. Cota, T.M. Alvarez, R. Ruller, R.A. Prade, F.M. Squina, M.T. Murakami, Molecular insights into substrate specificity and thermal stability of a bacterial GH5-CBM27 endo-1,4-beta-d-mannanase, J. Struct. Biol. 177 (2012) 469-476.

[54] M. McGavin, C.W. Forsberg, Isolation and characterization ofendoglucanases 1 and 2 from Bacteroides succinogenes S85, J. Bacteriol. 170 (1988) 2914-2922.

[55] V.C.T. Silva, A.L.S. Coto, R.C. Souza, M.B.S. Neves, E. Gomes, G.O. Bonilla-Rodriguez, Effect of $\mathrm{pH}$, temperature, and chemicals on the endoglucanases and beta-Glucosidases from the thermophilic fungus myceliophthora heterothallica F. 2. 4. obtained by solid-State and submerged cultivation, Biochem. Res. Int. 2016 (2016), 9 pages.

[56] M.R. Rubini, A.J.P. Dillon, C.M. Kyaw, F.P. Faria, M.J. Poças-Fonseca, I. Silva-Pereira, Cloning, characterization and heterologous expression of the first Penicillium echinulatum cellulase gene, J. Appl. Microbiol. 108 (2010) 1187-1198.

[57] T.K. Lee, C.H. Kim, Molecular cloning and expression of an endo- $\beta-1$, 4- d - glucanase i (Avicelase I) gene from bacillus cellulyticus K-12 and characterization of the recombinant enzyme, App. Biochem. Biotechnol. 80 (1999) 121-140.

[58] C. Béra-Maillet, L. Arthaud, P. Abad, M.N. Rosso, Biochemical characterization of MI-ENG1, a family 5 endoglucanase secreted by the root-knot nematode Meloidogyne incognita, Eur. J. Biochem. 267 (2000) 3255-3263.

[59] S.S. Ghatge, A.A. Telke, S.H. Kang, V. Arulalapperumal, K.W. Lee, S.P. Govindwar, Y. Um, D.B. Oh, H.D. Shin, S.W. Kim, Characterization of modular bifunctional processive endoglucanase Cel5 from Hahella chejuensis KCTC 2396, Appl. Microbiol. Biotechnol. 98 (2014) 4421-4435.

[60] A. Tejirian, F. Xu, Inhibition of cellulase-Catalyzed lignocellulosic hydrolysis by iron and oxidative metal ions and complexes, Appl. Environ. Microbiol. 76 (2010) 7673-7682.

[61] L.R. Lynd, P.J. Weimer, W.H. van Zyl, I.S. Pretorius, Microbial cellulose utilization: fundamentals and biotechnology, Microbiol. Mol. Biol. Rev. 66 (2002) 506-577.

[62] M.L. Sinnott, Catalytic mechanism of enzymic glycosyl transfer, Chem. Rev. 90 (1990) 1171-1202

[63] T. Tanabe, K. Morinaga, T. Fukamizo, M. Mitsutomi, Novel chitosanase from Streptomyces griseus HUT 6037 with transglycosylation activity, Biosci. Biotechnol. Biochem. 67 (2003) 354-364.

[64] R. Schröder, T.F. Wegrzyn, N.N. Sharma, R.G. Atkinson, LeMAN4 endo- $\beta$-mannanase from ripe tomato fruit can act as a mannan transglycosylase or hydrolase, Planta 224 (2006) 1091-1102.

[65] A. Dilokpimol, H. Nakai, C.H. Gotfredsen, M.J. Baumann, N. Nakai, M. Abou Hachem, B. Svensson, Recombinant production and characterisation of two related GH5 endo- $\beta-1,4$-mannanases from Aspergillus nidulans FGSC A4 showing distinctly different transglycosylation capacity, Biochim. Biophys. Acta - Proteins Proteomics. 1814 (2011) 1720-1729.

[66] G. Guinier, A. Fournet, Small-angle Scattering of X-ray, John Willey \& Sons Inc., New York, 1955

[67] J.O. Baker, J.R. McCarley, R. Lovett, C.-H. Yu, W.S. Adney, T.R. Rignall, T.B. Vinzant, S.R. Decker, J. Sakon, M.E. Himmel, Catalytically enhanced endocellulase Cel5A from Acidothermus cellulolyticus, Appl. Biochem. Biotechnol. 121-124 (2005) 129-148.

[68] J. Nicoll, D.A. Sawaya, M.R. Kwon, S. Cascio, D. Philipson, K.D. Abramson, The crystal structure of the primary $\mathrm{Ca} 2+$ sensor of the $\mathrm{Na}+/ \mathrm{Ca} 2+$ exchanger reveals a novel Ca2+ binding motif, J. Biol. Chem. 281 (2006) 21577-21581.

[69] M. Nei, S. Kumar, Molecular Evolution and Phylogenetics, Oxford Uni, New York, 2000. 